\title{
Comparative Results Between "Epi-Off" Accelerated and "Epi-Off" Standard Corneal Collagen Crosslinking-UVA in Progressive Keratoconus - 7 Years of Follow-Up
}

\author{
Cristina Ariadna Nicula (iD) 1,2 \\ Anca Maria Rednik (D) ${ }^{3}$ \\ Ariadna Patricia Nicula ${ }^{4}$ \\ Adriana Elena Bulboaca (iD ${ }^{5}$ \\ Dorin Nicula (iD ${ }^{2}$ \\ Karin Ursula Horvath (D) \\ 'Department of Ophthalmology, \\ Medicine and Pharmacy University "Iuliu \\ Hațieganu”, Cluj-Napoca, Romania; \\ ${ }^{2}$ Oculens Clinic, Cluj-Napoca, Romania; \\ ${ }^{3}$ Eye County Hospital, Department of \\ Ophthalmology, Cluj-Napoca, Romania; \\ ${ }^{4}$ Eye County Hospital, Department of \\ Ophthalmology, Arad, Romania; \\ ${ }^{5}$ Department of Pathophysiology, \\ Medicine and Pharmacy University "Iuliu \\ Hațieganu”, Cluj Napoca, Romania; \\ 'Department of Ophthalmology, \\ Medicine and Pharmacy Science and \\ Technology University "George Emil \\ Palade", Târgu Mureș, Romania
}

\begin{abstract}
Purpose: The purpose of the present study was to assess the long-term efficiency and safety of the "epi-off" accelerated CXL ( $9 \mathrm{~mW} / \mathrm{cm}^{2}$ for 10 minutes) in comparison to the standard "epi-off" CXL ( $3 \mathrm{~mW} / \mathrm{cm}^{2}$ for 30 minutes) in terms of topographical and keratometric parameters, refractive data and visual outcomes at 7 years of follow-up, in progressive keratoconus.

Material and Method: A retrospective and comparative study was performed. A total of 183 eyes from 183 patients with documented progressive keratoconus were included in the study. The patients were divided in two groups: 93 eyes from 93 patients underwent "epi-off" standard cross-linking technique $\left(3 \mathrm{~mW} / \mathrm{cm}^{2}\right.$ for 30 minutes) (S-CXL group) and 90 eyes from 90 patients underwent accelerated "epi-off" corneal CXL technique $\left(9 \mathrm{~mW} / \mathrm{cm}^{2}\right.$ for 10 minutes) (A-CXL group).
\end{abstract}

Results: Improvements in uncorrected distance visual acuity (UDVA) were statistically significant compared to baseline values in both groups at each time-point visit $(p=0.0421$ at 1 year, $p=0.0411$ at 7 years for A-CXL and $p=0.0375$ at 1 year, $p=0.0389$ at 7 years for S-CXL). At 7 years there was a statistically significant increase in CDVA ( $p=0.039$ in the A-CXL group and $p=0.0343$ in the S-CXL group at 7 years). Statistically significant reduction was noticed in Ksteep ( $p=0.0411$ in A-CXL group and $p=0.0224$ in S-CXL group), Kflat ( $p=0.0198$ in A-CXL group and $p=0.008$ in S-CXL group), $\mathrm{K}$ mean ( $p=0.0106$ in A-CXL group and $p=0.0193$ in $\mathrm{S}-\mathrm{CXL}$ group) and $\mathrm{Kmax}(p=0.0413$ in A-CXL group and $p=0.054$ in S-CXL group) at 7 years, compared to baseline values, in both groups, but without any statistically difference between the two procedures, at all time-point visits $(p>0.05)$.

Conclusion: The long-term outcomes of "epi-off" accelerated corneal collagen crosslinking-UVA ( $9 \mathrm{~mW} / \mathrm{cm}^{2}$ for 10 minutes) are similar to standard "epi-off" corneal collagen crosslinking procedure in the treatment of progressive keratoconus.

Keywords: progression, keratoconus, accelerated cross-linking, standard cross-linking

\section{Introduction}

Keratoconus $(\mathrm{KCN})$ is a bilateral ${ }^{1,2}$ and asymmetric ${ }^{3,4}$ corneal ectatic dystrophy, appearing in the second decade of life. It is defined by the thinning of the cornea, inducing an irregular astigmatism, corneal protrusion, biomechanical weakening and decreased visual acuity. ${ }^{5}$ Oftentimes, the onset is at puberty with a fast and severe progression. The corneal collagen cross-linking UVA (CXL) procedure was
Correspondence: Cristina Ariadna Nicula Department of Ophthalmology, Medicine and Pharmacy University "Iuliu

Hațieganu”, Cluj-Napoca, Romania

Tel +0II 40-722849575

Email niculacristina65@yahoo.com 
described for the first time in 1999 by Spoerl and Seiler ${ }^{6}$ and was introduced in order to stop the progression of keratoconus. The procedure combines the action of riboflavin (photosensitizing agent) with ultraviolet A light (UVA) in order to increase the strength and rigidity of the cornea. ${ }^{7}$ Several studies revealed the long-term outcomes regarding the efficacy and safety of the "epi-off" standard CXL (Dresden protocol) using $30 \mathrm{~min}$ of $3 \mathrm{~mW} /$ $\mathrm{cm}^{2}$ irradiation of UVA light. ${ }^{8-14}$ Different types of riboflavin substances were used since the CXL procedure was introduced in practice. A notable progress regarding riboflavin was the use of dextran-free substance as a consequence of the hyperoncotic effect of dextran which was associated with intraoperative decrease of corneal thickness and risk of stromal corneal wound-related complications. ${ }^{15}$ The use of hydroxypropyl methylcellulose rather than dextran has been demonstrated to prevent the corneal thickness reduction. ${ }^{16}$ Furthermore, the iontophoresis-assisted riboflavin utilized in the iontophoresis CXL was introduced in order to minimize the imbibition time. ${ }^{17}$ Since 2020 , the SafeCross ${ }^{\circledR}$ riboflavin solution $0.25 \%$ has been used for thin corneas (under $400 \mu \mathrm{m}$ ) and simultaneously combined the technique of CXL and trans-epithelial Excimer laser central corneal aberrometric remodeling. ${ }^{18}$ A recent preliminary study revealed the efficacy and safety of this solution in addition to the potential prevention of endothelium-toxic damage. ${ }^{19}$

Up to now, the CXL procedure is the only method to stop KCN progression. In order to reduce the time of the procedure, to improve convenience and comfort of the patients, the accelerated "epi-off" CXL technique performed in a pulsed or a continuous manner was introduced. $^{20,21}$ This novel protocol was acquired from the Bunsen-Roscoe law of reciprocity of photochemistry. ${ }^{22}$ In this regard, the accelerated procedure uses higher irradiation energy $\left(9 \mathrm{~mW} / \mathrm{cm}^{2}\right)$ in a shorter time (10 minutes) with a cumulative irradiation dose of 5.4 $\mathrm{J} / \mathrm{cm}^{2}$ and brief time for the instillation of riboflavin drops. ${ }^{23}$ Another type of A-CXL procedure using $15 \mathrm{~mW}$ pulsed-light CXL was shown to have efficacy and safety in the treatment of progressive $\mathrm{KCN} .{ }^{24}$ Pulsing of the UV light during CXL theoretically restarts the photodynamic reaction, therefore achieving an additional oxygen concentration, permitting more singlet oxygen release for CXL. ${ }^{25}$ Lately, a new combined procedure of selective transepithelial ablation with simultaneous accelerated CXL for corneal regularization of KCN (the STARE-X protocol) was introduced. ${ }^{26}$ The procedure was demonstrated to have efficacy in stopping the progression of $\mathrm{KCN}$, enhancing corneal regularity in a safer manner and improving visual outcomes and corneal aberrations. ${ }^{26}$

There are few studies demonstrating the efficacy and safety of "epi-off" accelerated CXL during a period of more than 2 years of follow-up. ${ }^{27-32}$ Furthermore, there are only some comparative studies with 12 months or greater followup $^{33,34}$ especially in comparison to standard CXL. ${ }^{34-36}$ Thus, there is a lack of clinical studies data on long-term outcomes of accelerated "epi-off" CXL $\left(9 \mathrm{~mW} / \mathrm{cm}^{2}, 10\right.$ min) versus standard "epi-off" CXL.

The purpose of the present study was to assess the long-term efficiency and safety of the "epi-off" accelerated CXL ( $9 \mathrm{~mW} / \mathrm{cm}^{2}$ for 10 minutes) in comparison to the standard "epi-off" CXL ( $3 \mathrm{~mW} / \mathrm{cm}^{2}$ for 30 minutes) in terms of topographical and keratometric parameters, refractive data and visual outcomes at 7 years of followup, in progressive keratoconus.

\section{Materials and Methods}

A retrospective, comparative, single-center study was conducted at the Oculens Clinic from Cluj-Napoca, Romania, was approved by the ethical committee of the clinic (No. 2/2021) and adhered to the principles proposed by the Declaration of Helsinki. Due to the retrospective nature of the study the ethical committee of the clinic ruled that no consent for participation was necessary. A total of 183 eyes from 183 patients with documented progressive KCN were included in the study. The patients were divided in 2 groups: the accelerated "epi-off" crosslinking group $\left(9 \mathrm{~mW} / \mathrm{cm}^{2}\right.$ for 10 minutes) (A-CXL) included 90 eyes from 90 patients, and the standard "epi-off" crosslinking ( $3 \mathrm{~mW} / \mathrm{cm}^{2}$ for 30 minutes) (S-CXL) group included 93 eyes from 93 patients. The patients were consecutively included in the study. The fellow eye was not included in the study, being diagnosed with fruste keratoconus or advanced keratoconus, thus not meeting the inclusion criteria. The patients underwent surgery between January 2012 and January 2014.

The inclusion criteria were: clinical $\mathrm{KCN}$ in patients older than 18 years, documented $\mathrm{KCN}$ progression and a corneal thickness more than $400 \mu \mathrm{m}$. A worsening in the last three to six months of follow-up was considered as progression criteria: myopia and astigmatism changes $>3$ $\mathrm{D}$, a mean change of central $\mathrm{K}$ value $>1.5 \mathrm{D}$ in three consecutive corneal topographic measurements, increase in the maximum keratometry (Kmax) in topography of more than $1 \mathrm{D}$ or a mean decrease in central corneal 
thickness $>5 \%$ in three consecutive tomographic measurements. ${ }^{37}$ The "Belin ABCD" grading system incorporated in the Oculus Pentacam topographer (Pentacam ${ }^{\circledR}$ HR Premium, Oculus Optikgerate $\mathrm{GmbH}$, Wetzlar, Germany) was used to establish the stage of $\mathrm{KCN}$, taking into account the anterior (" $\mathrm{A}$ ") and posterior radius of curvature (" $\mathrm{B}$ ") from a $3.0 \mathrm{~mm}$ zone centered on the thinnest point, "C" for the corneal thickness at the thinnest point and " $\mathrm{D}$ " for best corrected distance visual acuity. ${ }^{38,39}$ The exclusion criteria were: cases of $\mathrm{KCN}$ with corneal thickness under $400 \mu \mathrm{m}$, stromal scarring or acute hydrops, Vogt striae, history of herpetic keratitis, dry eye syndrome, cornea guttata, autoimmune diseases, breast feeding or pregnancy. Before the procedure all the patients underwent a complete ocular exam consisting of the uncorrected distance visual acuity (UDVA) and best corrected distance visual acuity (CDVA), refractometry (manifest and cycloplegic) (Topcon auto refracto-kerato-meter, KR 8900), keratometry (Pentacam ${ }^{\circledR}$ HR Premium, Oculus Optikgerate $\mathrm{GmbH}$, Wetzlar, Germany), slit lamp exam (Slit Lamp BX 900, Haag-Streit AG), eye fundus examination, intraocular pressure measured by applanation tonometry, corneal topography and tomography (Pentacam $^{\circledR}$ HR Premium, Oculus Optikgerate GmbH, Wetzlar, Germany), endothelial cell counting (Konan SP9000, Hyogo, Japan) and corneal thickness (Pentacam ${ }^{\circledR}$ HR Premium, Oculus Optikgerate GmbH, Wetzlar, Germany). For scientific purposes, the visual acuity was measured as logarithm of minimum angle of resolution. Patients were asked to interrupt the wear of contact lenses 2 weeks before the ocular assessment or surgery. All patients signed the specific informed consent before "epioff" accelerated or standard CXL procedure after a discussion regarding the steps of the procedure, effect of the technique upon the cornea and possible postoperative complications.

Before the surgery, all patients received a drop of $2 \%$ pilocarpine solution in the inferior conjunctival fornix in order to prevent a possible injury to the lens or the retina. After that a topical analgesic (alkaline solution), 3-4 drops, was instilled 15-20 minutes prior to the procedure. The "epi-off" CXL procedures were performed in the operating room [40 Mazzotta 2021-58]. After the mechanical corneal epithelial removal with a spatula, on an optical zone of $9.0 \mathrm{~mm}$ diameter in the center of the cornea, riboflavin $0.1 \%$-dextran $20 \%$ solution was instilled every 2 minutes for 20 minutes in the "epi-off" accelerated procedure and for 30 minutes in the "epi-off" standard technique. Afterwards, the eyes were exposed to ultraviolet rays (UVA) $370 \mathrm{~nm}$ under a power of $9 \mathrm{~mW} / \mathrm{cm}^{2}$ for 10 minutes in the "epi-off" accelerated procedure and under a power of $3 \mathrm{~mW} / \mathrm{cm}^{2}$ for 30 minutes in the "epi-off" standard technique. During irradiation, riboflavin $0.1 \%$ dextran 20\% solution was instilled every 2 minutes. Finally, the eyes were washed with saline solution, and a drop of antibiotic and steroids (Tobradex, Alcon Novartis, Dallas Worth, USA) was instilled. At the end of the procedure, a bandage contact lens was placed on the cornea for three days, until the cornea was totally healed. After the procedure, the patients received Tobradex (Alcon Novartis, Dallas Worth, USA) 5 times/day for one month, and a tapered dose and artificial tears for 6 months. After the procedure, all patients from both groups were examined at 24 hours, 3 days, 1, 6, 12 months and each year for 7 years. UDVA, CDVA, keratometric measurements (Ksteep, Kflat, Kmax) at Oculus Pentacam, ocular refraction exam (spherical equivalent), slit lamp examination, corneal tomography (topographic/tomographic indices, including the topographical cylinder) were measured at all time points. At one month after CXL procedure, anterior segment ocular coherence tomography (AS-OCT) analysis (Triton, Topcon, Japan) was performed in order to establish the penetration of the treatment, documenting the presence of the demarcation line. During the follow-up period, the efficacy of the CXL procedures in both groups was assessed by the Kmax values in addition to the topographic/tomographic parameters (Belin/Ambrosio Enhanced Ectasia Display [BAD_D], Ambrosio relational thickness [ART], thinnest point of the cornea [TP], index vertical asymmetry [IVA], index of surface variance [ISV], index of height asymmetry [IHA], index of height decentration [IHD], root mean square values [RMS] total) and the Belin ABCD progression display. ${ }^{41}$ Progression after CXL procedure was considered if two of the following criteria were present: increase of " $A$ " value, increase of "B" value or decrease of minimum corneal thickness evaluated with the ABCD progression display from Oculus Pentacam. $^{42}$

\section{Statistical Analysis}

Statistical analysis was performed using the PRISM 6.0 GraphPad software (GraphPad Holdings, LLC, California, USA). The data were described as mean \pm SD. All data passed the normality test. The comparison between the baseline parameters at each time point in both groups was done using an unpaired $t$-test. The statistical 
differences between baseline and post-CXL parameters in both groups were established with a paired $t$-test. For the entire research, a $p$ value of $<0.05$ was considered statistically significant.

\section{Results}

A total of 183 eyes from 183 patients were included in the study, divided in 2 groups, as mentioned above. In Table 1 the baseline characteristics are presented, including age, gender, KCN stages, the presence of atopy, Ksteep, Kflat, Kmax and spherical equivalent.

\section{Corneal Curvature Change}

Ksteep decreased by mean $1 \mathrm{D}$ and $1.64 \mathrm{D}$, respectively, in A-CXL group and S-CXL group at 7 years of follow-up. Kflat decreased by mean $0.88 \mathrm{D}$ and $1.37 \mathrm{D}$, respectively, in A-CXL group and S-CXL group at 7 years follow-up. In Figures 1 and 2 the trend of change in Ksteep and Kflat, respectively, over time, in both groups is shown. In comparison to the baseline values, the decrease of Ksteep was statistically significant at all time-point visits in both groups (Table 2).

There was no statistically significant difference between the two groups at each time-point visit $(p>0.05)$ (Table 3).

In comparison with the baseline values, the decrease of Kflat was statistically significant at all time-point visits in both groups (Table 2). There was no statistically significant difference between the two groups at each timepoint visit $(p>0.05)$ (Table 3$)$.

Kaverage (Kavg) decreased statistically significantly at 7 years' follow-up comparative to baseline values by a mean of 0.91 in the A-CXL group and 1.74 in S-CXL group (Tables 2 and 3 ).

Kmax decreased by mean 2.42 in A-CXL group and 2.23 in S-CXL group. The trend of change in Kmax over the follow-up period is shown in Figure 4. The decrease of Kmax was statistically significant in comparison to the baseline value at all time points in both groups (Table 2), but there were no statistically significant differences between A-CXL group and S-CXL group at each timepoint visit $(p>0.05)$ (Table 3$)$.

During the follow-up period, keratometric progression was present in 7 eyes (3.83\%): 4 eyes from A-CXL group and 3 eyes from S-CXL group. All patients developed allergic conjunctivitis with consecutive rubbing of the eye. In all these cases, we observed a progression of Kmax after 2-3 years, with a loss in CDVA of 1-2 lines. No re-treatment was performed in any of the cases.

In the A-CXL group, the cylinder decreased statistically significantly from baseline $-4.34 \pm 2.12 \mathrm{D}$ to -3.7 $\pm 2.12 \mathrm{D}$ at 7 years $(p=0.0311)$. In the S-CXL group the cylinder decreased from baseline $-3.72 \pm 2.16 \mathrm{D}$ to -2.98 $\pm 2.4 \mathrm{D}$ at 7 years $(p=0.0277)$ (Table 4$)$. There was no statistically significant difference between the two groups at each time-point visit $(p>0.05)$.

Table I Baseline Characteristics of the Patients

\begin{tabular}{|l|l|l|l|}
\hline Parameter & A-CXL & S-CXL & P value Between the Two Groups \\
\hline Number of eyes & 90 & 93 & \\
\hline Men, $n$ (\%) & $46(51.1 \%)$ & $50(53.76 \%)$ & 0.643 \\
\hline Mean age (years) & $35 \pm 5.7$ & $37 \pm 6.1$ & 0.388 \\
\hline Keratoconus stage, $n(\%)$ & & & \\
0 & $10(11.11 \%)$ & $12(12.90 \%)$ & 0.528 \\
I & $39(43.33 \%)$ & $41(44.09 \%)$ & 0.638 \\
II & $41(45.56 \%)$ & $40(43.01 \%)$ & 0.622 \\
\hline Presence of atopy, $n$ (\%) & $38(42.22 \%)$ & $43(46.23 \%)$ & 0.302 \\
Kflat (D) & $46.08 \pm 4.55$ & $46.70 \pm 4.12$ & 0.366 \\
Ksteep (D) & $49.09 \pm 4.92$ & $50.98 \pm 4.42$ & 0.153 \\
Kavg (D) & $47.59 \pm 4.4$ & $48.84 \pm 3.89$ & 0.438 \\
Kmax (D) & $53.74 \pm 5.36$ & $56.56 \pm 5.61$ & 0.765 \\
SE (D) & $-4.95 \pm 3.65$ & $-5.55 \pm 3.88$ & 0.6892 \\
Mean cylinder(D) & $-3.72 \pm 2.16$ & $-4.34 \pm 2.12$ & 0.5681 \\
\hline
\end{tabular}

Abbreviations: A-CXL, Epi-off accelerated CXL; S-CXL, Epi-off standard CXL; Kflat, keratometry on the flat meridian; Ksteep, keratometry on the steep meridian; Kavg, media between both keratometries; Kmax, maximum keratometry; SE, spherical equivalent; $D$, diopters. 


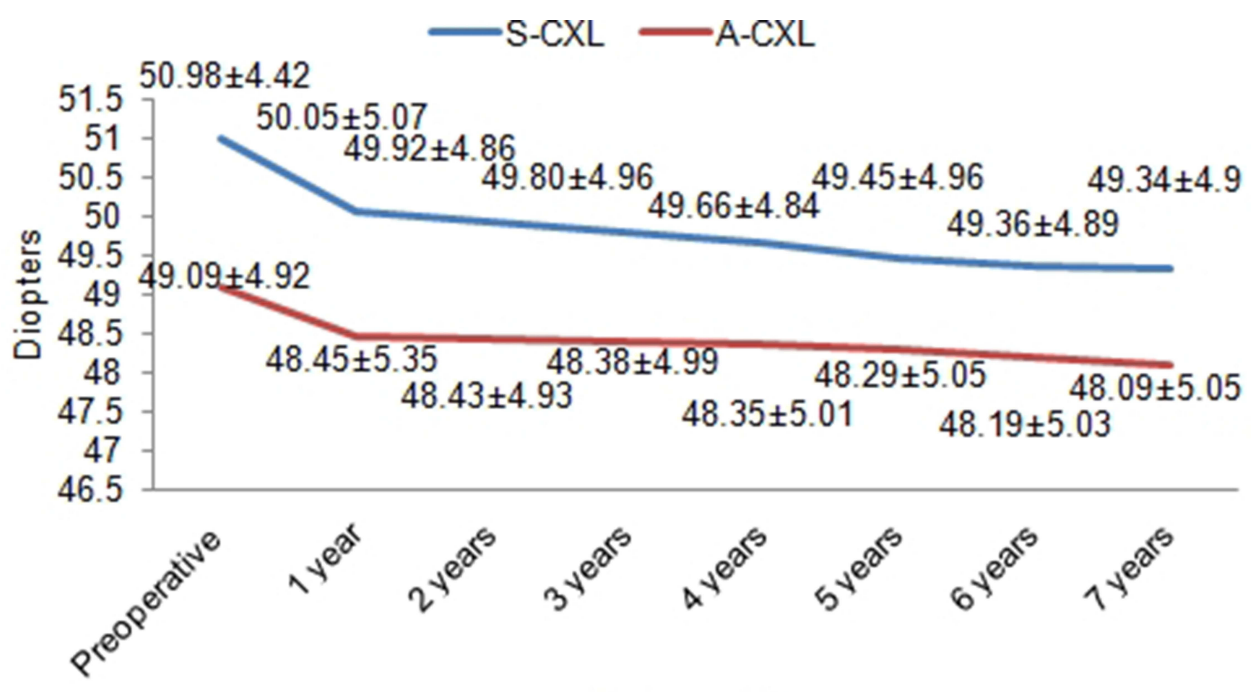

Timepoint

Figure I Evolution of Ksteep in both groups.

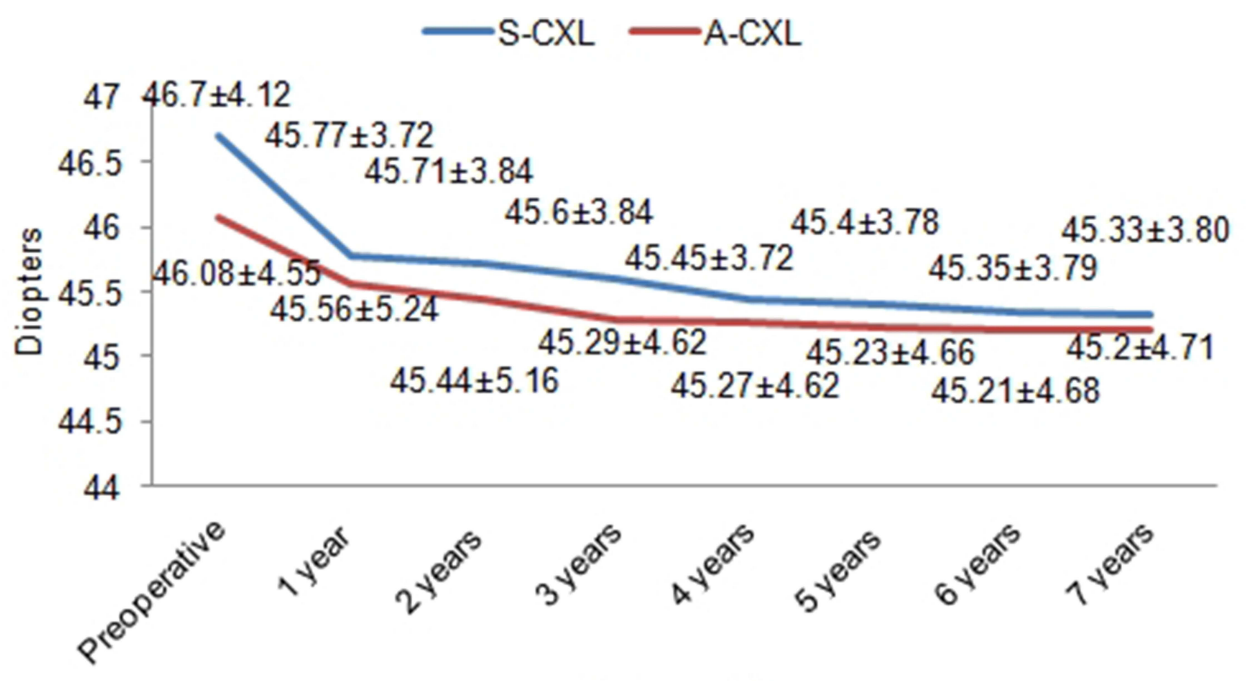

Timepoint

Figure 2 Evolution of Kflat in both groups.

In the A-CXL group, the mean SE decreased statistically significantly from $-5.55 \pm 3.88 \mathrm{D}$ to $-4.77 \pm 3.44 \mathrm{D}$ at 7 years $(p=0.015)$. In the S-CXL group, the SE decreased statistically significantly from $-4.95 \pm 3.65 \mathrm{D}$ to $-4.21 \pm 3.34 \mathrm{D}$ at 7 years $(p=0.0197)$. Regarding the SE, we did not notice any statistically significant difference between the two groups at each time-point visit $(p>0.05)$.

The evolution of cylinder and SE is shown in Table 4.

\section{Corneal Topographical Indices Change}

Topographical indices such as thinnest corneal point (TP), corneal volume (CV), index vertical asymmetry (IVA), index of surface variance (ISV), index of height asymmetry (IHA), index of height decentration (IHD), Belin/Ambrosio enhanced ectasia display (BAD_D) and Ambrosio relational thickness (ART Max) were statistically significantly decreased compared to baseline values at all visits, in both groups (Table 5). There was no statistically significant difference between the two groups at each time-point visit $(p>0.05)$. The changes in total high ocular aberration (HOA) and root mean square values (RMS) decreased statistically significantly at 7 years, comparative to baseline values, in both groups ( $p=0.0309$ in A-CXL group and $p=0.02$ in $\mathrm{S}-\mathrm{CXL}$ group). 


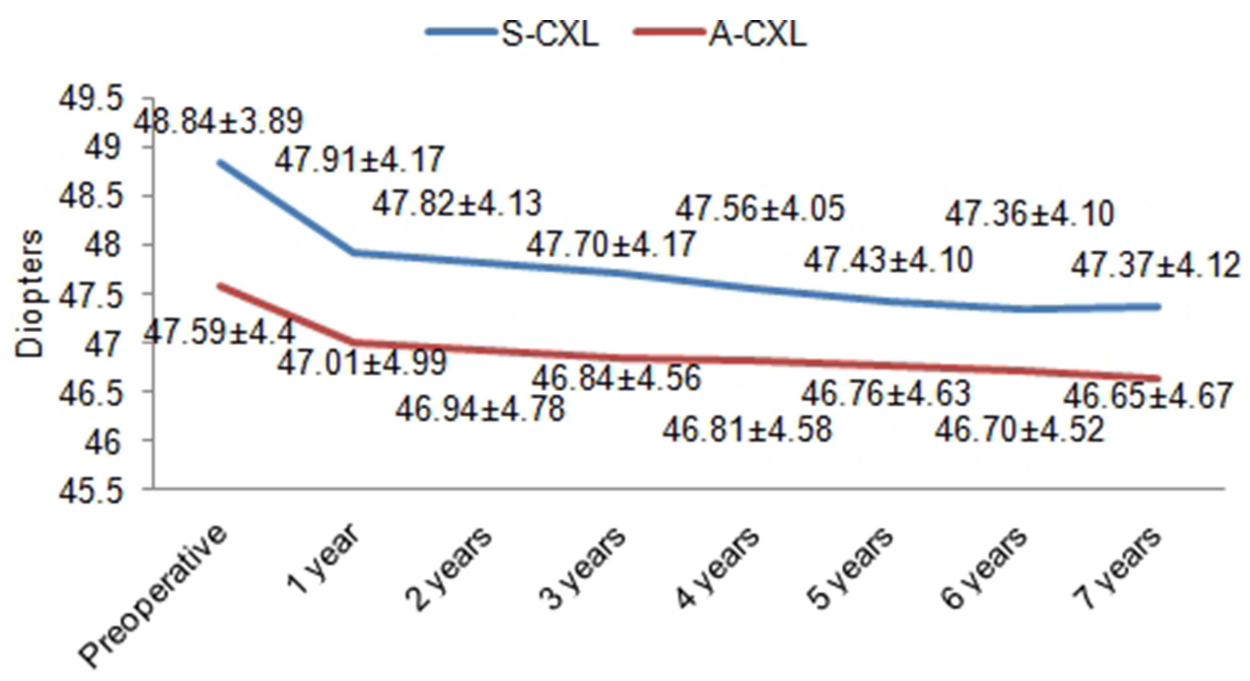

Timepoint

Figure 3 Evolution of Kavg in both groups.

No statistically significant difference was present between the two groups ( $p>0.05$ at each time point) (Table 5 ).

\section{Visual Acuity Change}

Improvements in UDVA were statistically significant compared to baseline values in both groups at each time-point visit ( $p=0.0421$ at 1 year, $p=0.0389$ at 7 years) (Figure 5).

Improvements in CDVA were statistically significant compared to baseline values in both groups at each time-point visit ( $p=0.045$ at 1 year, 0.0343 at 7 years for S-CXL) (Figure 6).

The improvements in CDVA were not statistically significantly different between the two groups ( $p=0.644$ at 1 year, $p=0.589$ at 2 years, $p=0.3371$ at 3 years, $p=0.6621$ at 4 years, $p=0.0711$ at 5 years, $p=0.674$ at 6 years, $p=0.0575$ at 7 years).

\section{Corneal Thickness Change}

There was no statistically significant difference in the postoperative central corneal thickness at 7 years of follow-up in the two groups $(p=0.12)$.

\section{Demarcation Line}

The demarcation line was indentified at a mean depth of $203 \pm 12.03 \mu \mathrm{m}$ in the A-CXL group and $211 \pm 13.2 \mu \mathrm{m}$ in S-CXL group.

There were no cases of corneal melting, persistent epithelial defect, corneal decompensation or other adverse events. Transitory corneal haze was present in the majority of cases $(75.3 \%)$ but disappeared after 6 months after both procedures of CXL.

Table $2 P$ values Comparing Each Time Point with Baseline

\begin{tabular}{|l|c|c|c|c|c|c|c|c|}
\hline \multirow{2}{*}{ Time Point } & \multicolumn{2}{|c|}{ Kflat } & \multicolumn{2}{c|}{ Ksteep } & \multicolumn{2}{c|}{ Kavg } & \multicolumn{2}{c|}{ Kmax } \\
\cline { 2 - 8 } & S-CXL & A-CXL & S-CXL & A-CXL & S-CXL & A-CXL & S-CXL & A-CXL \\
\hline I year & $0.010 I^{*}$ & $0.0284^{*}$ & $0.0092^{*}$ & $0.032 I^{*}$ & $0.005^{*}$ & $0.037^{*}$ & $0.0308^{*}$ & $0.0302^{*}$ \\
2 years & $0.0085^{*}$ & $0.0188^{*}$ & $0.0125^{*}$ & $0.0402^{*}$ & $0.0079^{*}$ & $0.027^{*}$ & $0.0265^{*}$ & $0.0344^{*}$ \\
3 years & $0.007^{*}$ & $0.0212^{*}$ & $0.0235^{*}$ & $0.0376^{*}$ & $0.0126^{*}$ & $0.0154^{*}$ & $0.0292^{*}$ & $0.0358^{*}$ \\
4 years & $0.0112^{*}$ & $0.0145^{*}$ & $0.0166^{*}$ & $0.0295^{*}$ & $0.0177^{*}$ & $0.0201^{*}$ & $0.032 I^{*}$ & $0.0389^{*}$ \\
5 years & $0.0095^{*}$ & $0.0229^{*}$ & $0.0227^{*}$ & $0.0322^{*}$ & $0.0153^{*}$ & $0.0174^{*}$ & $0.034 I^{*}$ & $0.0402^{*}$ \\
6 years & $0.0064^{*}$ & $0.0147^{*}$ & $0.019^{*}$ & $0.0393^{*}$ & $0.0145^{*}$ & $0.014^{*}$ & $0.033^{*}$ & $0.0379^{*}$ \\
7 years & $0.008^{*}$ & $0.0198^{*}$ & $0.0224^{*}$ & $0.0224^{*}$ & $0.0193^{*}$ & $0.0106^{*}$ & $0.045^{*}$ & $0.0413^{*}$ \\
\hline
\end{tabular}

Note: *Statistically significant $(p<0.05)$. 


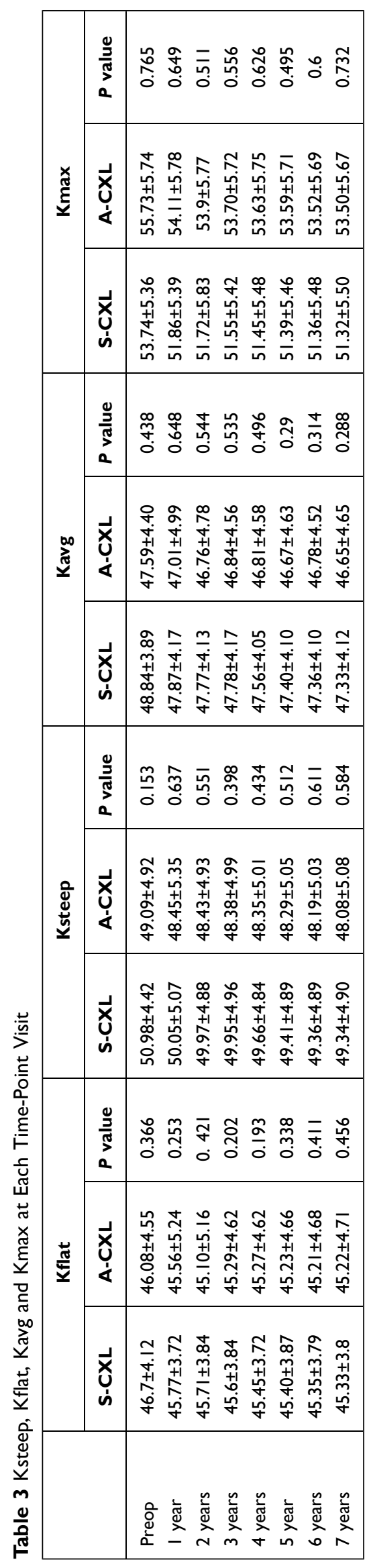

\section{Discussion}

Several long-term studies have established the efficacy and safety of the S-CXL UVA procedure in the treatment of KCN. ${ }^{8,13,14,43}$ Moreover, Elmassry et $\mathrm{al}^{44}$ in a long-term study showed that the CXL procedure is an effective method to prevent the progression of corneal ectasia, regardless of the type of ectasia. The idea of A-CXL was introduced by Schumacher et $\mathrm{al}^{45}$ in an experimental animal model, demonstrating the same efficacy in terms of corneal stiffening between the Dresden protocol (S-CXL) and A-CXL. By introducing the "epi-off" A-CXL, the procedure duration was shortened and the irradiation energy rose. There are comparative studies demonstrating similar results between the S-CXL and A-CXL. ${ }^{33,46-48}$

Our study revealed a statistically significant reduction of Kmax (2.23 in S-CXL and 2.42 in A-CXL), Kflat (1.37 in S-CXL and 0.88 in A-CXL), Ksteep (1.64 in S-CXL and 1 in A-CXL) and Kmean (1.74 in S-CXL and 0.91 in A-CXL) in comparison to the baseline values at 7 years of follow-up in both groups, without any statistically significant difference between the two groups ( $p>0.05$ at each time point). Similar results were demonstrated by Ting et $\mathrm{al}^{49}$ reporting a significant decrease of Kmax (-1.68), Ksteep $(-0.64)$ and Kmean $(-0.50)$ at 24 months of follow-up. In a comparative study between A-CXL $\left(18 \mathrm{~mW} / \mathrm{cm}^{2}\right)$ and S-CXL, Hashemi et a ${ }^{50}$ demonstrated that the decrease in Kmax values was not statistically significantly different between the two groups. Furthermore, Sarac et $\mathrm{al}^{48}$ and Vounotripidis et $\mathrm{al}^{51}$ revealed important improvement of Kmax from -0.3 to -1.4 D after A-CXL. Moreover, Males et al ${ }^{47}$ revealed a statistically significant decrease in Ksteep values after both A-CXL (51.19 \pm 6.01 to $49.95 \pm 4.90)$ and S-CXL ( $48.50 \pm 2.92$ to $47.89 \pm 3.62$ ), with no difference between the groups at 30 months after treatment. Similarly, in a prospective, interventional study, Mazzotta et al ${ }^{24}$ compared the outcomes of "epi-off" pulsed A-CXL at $30 \mathrm{~mW} / \mathrm{cm}^{2} \mathrm{UVA}$ exposure for $8 \mathrm{~min}$ versus continuous-light A-CXL at $30 \mathrm{~mW} / \mathrm{cm}^{2}$ UVA exposure for $4 \mathrm{~min}$. Their conclusion was that the "epi-off" pulsed A-CXL offered better results in terms of keratometric values, topographical indices and stromal penetration by optimizing oxygen availability during the procedure. Moreover, Elbaz et al ${ }^{52}$ showed that after A-CXL $\left(9 \mathrm{~mW} / \mathrm{cm}^{2}, 10 \mathrm{~min}\right)$ stable keratometric values were achieved. Furthermore, Alnawaiseh et $\mathrm{al}^{53}$ revealed stable CDVA and decrease of keratometric values after the same procedure after 21.7 months of follow-up. In a comparative study of high-fluence A-CXL $\left(7 \mathrm{~mW} / \mathrm{cm}^{2} \mathrm{UVA}\right.$ irradiation) versus S-CXL, Kanellopoulos et $\mathrm{al}^{54}$ demonstrated 


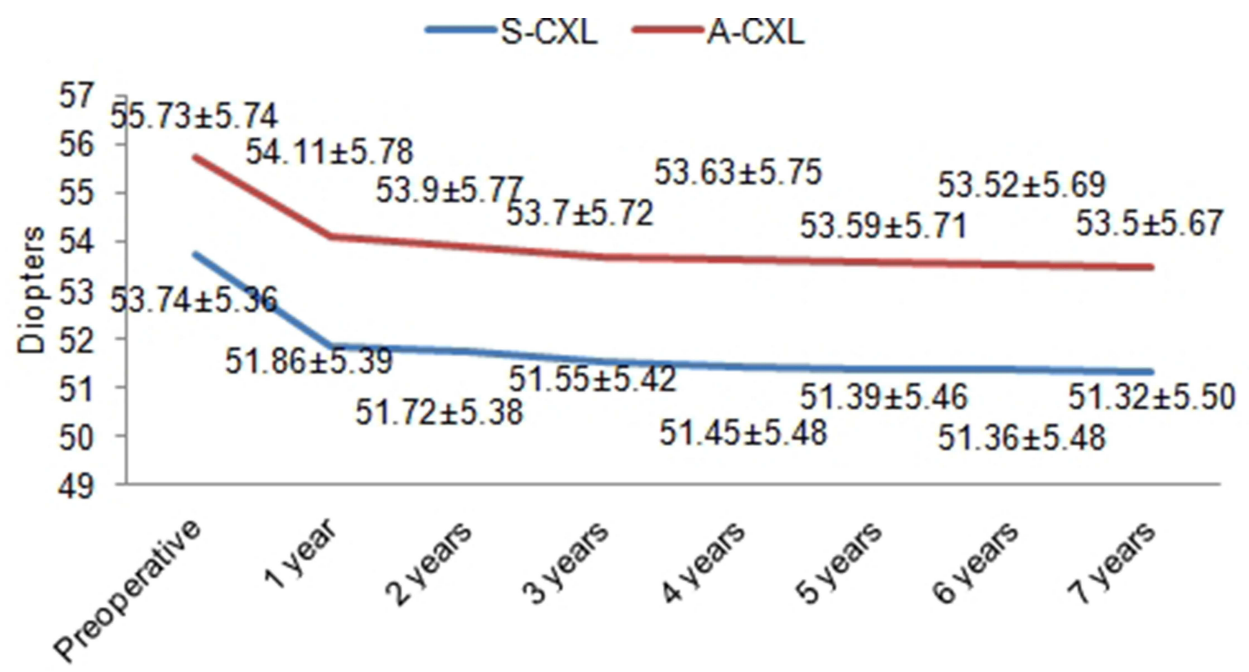

Timepoint

Figure 4 Evolution of Kmax in both groups.

a statistically significant decrease in Ksteep and SE and an increase of CDVA in both procedures. Conflicting studies ${ }^{46,51}$ showed a non-significant improvement of Kmean following A-CXL after 3 years of follow-up. Cummings et $\mathrm{al}^{34}$ revealed a statistically significant corneal flattening after A-CXL in comparison to the S-CXL at 1 year follow-up. Recent findings by Chan et $\mathrm{al}^{55}$ revealed that A-CXL gives better keratometry flattening, being more efficient in advanced $\mathrm{KCN}$ compared to mild or moderate stages. Chow et $\mathrm{al}^{35}$ demonstrated that S-CXL $\left(18 \mathrm{~mW} / \mathrm{cm}^{2}\right)$ gave a better corneal flattening effect compared to the A-CXL procedure.

Our findings showed that the SE decreased statistically significantly from baseline up to 7-year follow-up in both groups $(p<0.05)$, but with no statistically significant difference between the two procedures at each time point $(p>0.05)$. Similar results were reported by Males et $\mathrm{al}^{47}$

Table 4 The Evolution of Cylinder and Spherical Equivalent from Baseline to 7 Year Follow-Up Time Point in Both Groups

\begin{tabular}{|c|c|c|c|c|c|c|}
\hline Parameter & Time Point & A-CXL & $\begin{array}{l}P \text { value } \\
\text { Compared to } \\
\text { Baseline }\end{array}$ & S-CXL & $\begin{array}{l}P \text { value } \\
\text { Compared to } \\
\text { Baseline }\end{array}$ & $\begin{array}{l}P \text { value } \\
\text { Between } \\
\text { Groups }\end{array}$ \\
\hline \multirow[t]{8}{*}{ Cylinder (D) } & Preoperative & $-4.34 \pm 2.12$ & - & $-3.72 \pm 2.16$ & - & $0.568 \mathrm{I}$ \\
\hline & I year & $-4.26 \pm 2.34$ & $0.0467^{*}$ & $-3.64 \pm 1.75$ & $0.0389 *$ & 0.4722 \\
\hline & 2 years & $-4.12 \pm 1.95$ & $0.0401 *$ & $-3.48 \pm 1.93$ & $0.035^{*}$ & 0.492 \\
\hline & 3 years & $-4.05 \pm 2.08$ & $0.0376^{*}$ & $-3.33 \pm 2.19$ & $0.0331 *$ & 0.5017 \\
\hline & 4 years & $-3.95 \pm 2.5$ & $0.0344^{*}$ & $-3.2 \pm 2.44$ & $0.0303^{*}$ & 0.5133 \\
\hline & 5 years & $-3.88 \pm 2.3$ & $0.0327^{*}$ & $-3.15 \pm 2.56$ & $0.0296 *$ & 0.5198 \\
\hline & 6 years & $-3.78 \pm 2.29$ & $0.032 *$ & $-3.03 \pm 2.5$ & $0.0286^{*}$ & 0.5039 \\
\hline & 7 years & $-3.7 \pm 2.12$ & $0.0311^{*}$ & $-2.98 \pm 2.4$ & $0.0277^{*}$ & 0.4896 \\
\hline \multirow[t]{8}{*}{ SE (D) } & Preoperative & $-5.55 \pm 3.88$ & - & $-4.95 \pm 3.65$ & - & 0.6892 \\
\hline & I year & $-5.28 \pm 3.73$ & $0.0257^{*}$ & $-4.74 \pm 3.81$ & $0.0294 *$ & 0.7113 \\
\hline & 2 years & $-5.14 \pm 3.65$ & $0.0224^{*}$ & $-4.6 I \pm 3.82$ & $0.0275^{*}$ & 0.7349 \\
\hline & 3 years & $-4.94 \pm 3.42$ & $0.0208^{*}$ & $-4.46 \pm 3.42$ & $0.0258^{*}$ & 0.7407 \\
\hline & 4 years & $-4.9 \pm 3.61$ & $0.021 *$ & $-4.38 \pm 3.43$ & $0.0213^{*}$ & 0.7228 \\
\hline & 5 years & $-4.85 \pm 3.54$ & $0.0196 *$ & $-4.32 \pm 3.4$ & $0.02 *$ & 0.7502 \\
\hline & 6 years & $-4.8 I \pm 3.49$ & $0.0169 *$ & $-4.26 \pm 3.42$ & $0.0211 *$ & 0.6983 \\
\hline & 7 years & $-4.77 \pm 3.44$ & $0.015^{*}$ & $-4.21 \pm 3.34$ & $0.0197^{*}$ & 0.7288 \\
\hline
\end{tabular}

Note: *Statistically significant $(p<0.05)$.

Abbreviation: SE, spherical equivalent. 
Table 5 Topographical and Tomographical Parameters Evolution from Baseline to the Final Visit

\begin{tabular}{|c|c|c|c|c|c|c|}
\hline Parameter & Time Point & A-CXL & $\begin{array}{l}P \text { value Compared } \\
\text { to Baseline }\end{array}$ & S-CXL & $\begin{array}{l}P \text { value Compared } \\
\text { to Baseline }\end{array}$ & $\begin{array}{l}P \text { value } \\
\text { Between Groups }\end{array}$ \\
\hline $\mathrm{TP}(\mu \mathrm{m})$ & $\begin{array}{l}\text { Preoperative } \\
1 \text { year } \\
2 \text { years } \\
3 \text { years } \\
4 \text { years } \\
5 \text { years } \\
6 \text { years } \\
7 \text { years }\end{array}$ & $\begin{array}{l}463.29 \pm 33.65 \\
449.98 \pm 31.79 \\
447.23 \pm 31.72 \\
443.56 \pm 39.34 \\
442.47 \pm 39.29 \\
442.24 \pm 39.30 \\
442.10 \pm 39.31 \\
441.06 \pm 39.7\end{array}$ & $\begin{array}{l}- \\
0.0104^{*} \\
0.0019^{*} \\
0.0003^{*} \\
<0.000 I^{*} \\
<0.000 I^{*} \\
<0.000 I^{*} \\
<0.0001 *\end{array}$ & $\begin{array}{l}462.42 \pm 34.36 \\
445.04 \pm 38.89 \\
443.56 \pm 38.71 \\
442.22 \pm 38.61 \\
441.01 \pm 38.69 \\
440.7 \pm 38.6 \\
440.69 \pm 38.6 \\
440.66 \pm 38.59\end{array}$ & $\begin{array}{l}- \\
0.0015^{*} \\
0.0006^{*} \\
0.0002^{*} \\
<0.000 I^{*} \\
<0.000 I^{*} \\
<0.000 I^{*} \\
<0.0001 *\end{array}$ & $\begin{array}{l}0.9908 \\
0.3889 \\
0.2527 \\
0.9811 \\
0.8811 \\
0.8613 \\
0.8825 \\
0.8994\end{array}$ \\
\hline $\operatorname{Vol} C\left(\mathrm{~mm}^{3}\right)$ & $\begin{array}{l}\text { Preoperative } \\
1 \text { year } \\
2 \text { years } \\
3 \text { years } \\
4 \text { years } \\
5 \text { years } \\
6 \text { years } \\
7 \text { years }\end{array}$ & $\begin{array}{l}56.863 \pm 4.48 \\
55.679 \pm 3.28 \\
55.343 \pm 3.27 \\
54.966 \pm 3.62 \\
54.943 \pm 3.64 \\
54.921 \pm 3.67 \\
54.908 \pm 3.69 \\
54.899 \pm 3.71\end{array}$ & $\begin{array}{l}0.0138^{*} \\
0.0016^{*} \\
0.0002^{*} \\
0.0002^{*} \\
0.0001^{*} \\
0.0001^{*} \\
0.0001^{*}\end{array}$ & $\begin{array}{l}57.419 \pm 6.55 \\
56.133 \pm 6.56 \\
56.1 \pm 6.54 \\
56.067 \pm 6.55 \\
56.061 \pm 6.50 \\
56.053 \pm 6.56 \\
56.041 \pm 6.57 \\
56.037 \pm 5.78\end{array}$ & $\begin{array}{l}0.0182^{*} \\
0.017^{*} \\
0.0160^{*} \\
0.0159^{*} \\
0.0157^{*} \\
0.0153^{*} \\
0.0152^{*}\end{array}$ & $\begin{array}{l}0.4708 \\
0.5529 \\
0.3211 \\
0.1580 \\
0.1519 \\
0.1481 \\
0.1487 \\
0.1473\end{array}$ \\
\hline IVA $(\mu \mathrm{m})$ & $\begin{array}{l}\text { Preoperative } \\
1 \text { year } \\
2 \text { years } \\
3 \text { years } \\
4 \text { years } \\
5 \text { years } \\
6 \text { years } \\
7 \text { years }\end{array}$ & $\begin{array}{l}0.984 \pm 0.35 \\
0.834 \pm 0.36 \\
0.826 \pm 0.3 \\
0.819 \pm 0.29 \\
0.812 \pm 0.31 \\
0.805 \pm 0.33 \\
0.797 \pm 0.35 \\
0.795 \pm 0.3\end{array}$ & $\begin{array}{l}0.0012^{*} \\
0.0007^{*} \\
0.0004^{*} \\
0.0002^{*} \\
0.000 I^{*} \\
<0.000 I^{*} \\
<0.000 I^{*}\end{array}$ & $\begin{array}{l}0.896 \pm 0.4 \mid \\
0.757 \pm 0.4 \\
0.747 \pm 0.4 \mid \\
0.737 \pm 0.4 \\
0.727 \pm 0.42 \\
0.7 \mid 9 \pm 0.43 \\
0.7 \mid 4 \pm 0.4 \\
0.7|2 \pm 0.4|\end{array}$ & $\begin{array}{l}0.0221^{*} \\
0.0140^{*} \\
0.0090^{*} \\
0.0056^{*} \\
0.0037^{*} \\
0.0036^{*} \\
0.0029 *\end{array}$ & $\begin{array}{l}0.1052 \\
0.1535 \\
0.1390 \\
0.1280 \\
0.1161 \\
0.1110 \\
0.1201 \\
0.1183\end{array}$ \\
\hline ISV $(\mu \mathrm{m})$ & $\begin{array}{l}\text { Preoperative } \\
1 \text { year } \\
2 \text { years } \\
3 \text { years } \\
4 \text { years } \\
5 \text { years } \\
6 \text { years } \\
7 \text { years }\end{array}$ & $\begin{array}{l}86.459 \pm 27.30 \\
80.953 \pm 26.61 \\
78.956 \pm 26.58 \\
77.954 \pm 26.51 \\
77.9 \pm 26.45 \\
77.859 \pm 26.61 \\
77.834 \pm 26.46 \\
77.803 \pm 26.67\end{array}$ & $\begin{array}{l}0.1386 \\
0.0448 * \\
0.0233^{*} \\
0.0226 * \\
0.0221 * \\
0.0220 * \\
0.0216 *\end{array}$ & $\begin{array}{l}79.140 \pm 29.81 \\
75.355 \pm 29.84 \\
74.366 \pm 29.83 \\
73.527 \pm 29.86 \\
72.946 \pm 29.87 \\
72.452 \pm 29.88 \\
72.409 \pm 29.94 \\
72.366 \pm 30.01\end{array}$ & $\begin{array}{l}0.0388^{*} \\
0.0267^{*} \\
0.0201^{*} \\
0.0158^{*} \\
0.0128^{*} \\
0.0126^{*} \\
0.0124^{*}\end{array}$ & $\begin{array}{l}0.0758 \\
0.1753 \\
0.2674 \\
0.2850 \\
0.2301 \\
0.1894 \\
0.1875 \\
0.1877\end{array}$ \\
\hline $\mathrm{IHA}(\mu \mathrm{m})$ & $\begin{array}{l}\text { Preoperative } \\
1 \text { year } \\
2 \text { years } \\
3 \text { years } \\
4 \text { years } \\
5 \text { years } \\
6 \text { years } \\
7 \text { years }\end{array}$ & $\begin{array}{l}34.836 \pm 24.37 \\
28.656 \pm 21.06 \\
26.48 I \pm 20.25 \\
25.787 \pm 20.9 \\
25.780 \pm 20.9 \\
25.77 I \pm 20.89 \\
25.764 \pm 20.87 \\
25.76 I \pm 20.8\end{array}$ & $\begin{array}{l}0.0057^{*} \\
0.0075^{*} \\
0.0043^{*} \\
0.0043^{*} \\
0.0042^{*} \\
0.0042^{*} \\
0.0042^{*}\end{array}$ & $\begin{array}{l}31.011 \pm 21.28 \\
27.643 \pm 20.53 \\
27.288 \pm 20.38 \\
27.006 \pm 20.32 \\
26.758 \pm 20.27 \\
26.520 \pm 20.25 \\
26.509 \pm 20.21 \\
26.498 \pm 20.22\end{array}$ & $\begin{array}{l}0.0273 * \\
0.0224 * \\
0.0190^{*} \\
0.0164 * \\
0.0142^{*} \\
0.0140 * \\
0.0139 *\end{array}$ & $\begin{array}{l}0.2390 \\
0.7327 \\
0.7811 \\
0.6785 \\
0.7391 \\
0.7985 \\
0.7994 \\
0.8018\end{array}$ \\
\hline BAD_D & $\begin{array}{l}\text { Preoperative } \\
1 \text { year } \\
2 \text { years } \\
3 \text { years } \\
4 \text { years } \\
5 \text { years } \\
6 \text { years } \\
7 \text { years }\end{array}$ & $\begin{array}{l}8.202 \pm 3.37 \\
7.923 \pm 3.32 \\
7.842 \pm 3.29 \\
7.776 \pm 3.21 \\
7.727 \pm 3.33 \\
7.679 \pm 3.4 \\
7.647 \pm 3.36 \\
7.616 \pm 3.31\end{array}$ & $\begin{array}{l}0.0568 * \\
0.0463^{*} \\
0.0386^{*} \\
0.0334^{*} \\
0.0289 * \\
0.0263^{*} \\
0.0238^{*}\end{array}$ & $\begin{array}{l}7.828 \pm 3.13 \\
7.58 \pm 3.03 \\
7.485 \pm 3.15 \\
7.398 \pm 3.18 \\
7.319 \pm 3.21 \\
7.248 \pm 3.28 \\
7.194 \pm 3.32 \\
7.141 \pm 3.38\end{array}$ & $\begin{array}{l}0.0642^{*} \\
0.0574^{*} \\
0.052^{*} \\
0.0479^{*} \\
0.0457^{*} \\
0.0450^{*} \\
0.0443^{*}\end{array}$ & $\begin{array}{l}0.4530 \\
0.4322 \\
0.4339 \\
0.4346 \\
0.4341 \\
0.4376 \\
0.4351 \\
0.4338\end{array}$ \\
\hline
\end{tabular}


Table 5 (Continued).

\begin{tabular}{|c|c|c|c|c|c|c|}
\hline Parameter & Time Point & A-CXL & $\begin{array}{l}P \text { value Compared } \\
\text { to Baseline }\end{array}$ & S-CXL & $\begin{array}{l}P \text { value Compared } \\
\text { to Baseline }\end{array}$ & $\begin{array}{l}P \text { value } \\
\text { Between Groups }\end{array}$ \\
\hline $\begin{array}{l}\text { ART Max } \\
(\mu \mathrm{m})\end{array}$ & $\begin{array}{l}\text { Preoperative } \\
1 \text { year } \\
2 \text { years } \\
3 \text { years } \\
4 \text { years } \\
5 \text { years } \\
6 \text { years } \\
7 \text { years }\end{array}$ & $\begin{array}{l}|7| .29 \pm 57.87 \\
|53.46 \pm 50.5| \\
\mid 50.05 \pm 50.58 \\
\mid 45.50 \pm 50.04 \\
\mid 44.97 \pm 49.93 \\
|44.44 \pm 49.6| \\
|44.3| \pm 49.66 \\
\mid 44.1849 .73\end{array}$ & $\begin{array}{l}0.0175^{*} \\
0.0049^{*} \\
0.0006^{*} \\
0.0005^{*} \\
0.0004^{*} \\
0.0003^{*} \\
0.0003^{*}\end{array}$ & $\begin{array}{l}174.624 \pm 67.38 \\
163.462 \pm 67.06 \\
161.495 \pm 67.06 \\
160.022 \pm 67.16 \\
158.914 \pm 67.14 \\
158.398 \pm 67.19 \\
158.344 \pm 67.21 \\
158.323 \pm 67.22\end{array}$ & $\begin{array}{l}0.0259^{*} \\
0.0184^{*} \\
0.0140^{*} \\
0.0113^{*} \\
0.0101 * \\
0.0107^{*} \\
0.007^{*}\end{array}$ & $\begin{array}{l}0.7084 \\
0.2410 \\
0.1830 \\
0.0892 \\
0.1046 \\
0.1017 \\
0.1005 \\
0.0986\end{array}$ \\
\hline IHD $(\mu \mathrm{m})$ & $\begin{array}{l}\text { Preoperative } \\
1 \text { year } \\
2 \text { years } \\
3 \text { years } \\
4 \text { years } \\
5 \text { years } \\
6 \text { years } \\
7 \text { years }\end{array}$ & $\begin{array}{l}0.154 \pm 0.149 \\
0.133 \pm 0.133 \\
0.132 \pm 0.131 \\
0.131 \pm 0.129 \\
0.129 \pm 0.13 \\
0.128 \pm 0.131 \\
0.127 \pm 0.128 \\
0.127 \pm 0.131\end{array}$ & $\begin{array}{l}0.0451^{*} \\
0.0348^{*} \\
0.0322^{*} \\
0.0303^{*} \\
0.0388^{*} \\
0.0412^{*} \\
0.0402^{*} \\
0.041^{*}\end{array}$ & $\begin{array}{l}0.159 \pm 0.152 \\
0.136 \pm 0.132 \\
0.134 \pm 0.128 \\
0.134 \pm 0.126 \\
0.133 \pm 0.128 \\
0.131 \pm 0.13 \\
0.130 \pm 0.131 \\
0.130 \pm 0.13\end{array}$ & $\begin{array}{l}0.0331^{*} \\
0.0146^{*} \\
0.0178^{*} \\
0.019^{*} \\
0.0232^{*} \\
0.0244^{*} \\
0.0263^{*} \\
0.0273^{*}\end{array}$ & $\begin{array}{l}0.0678 \\
0.0634 \\
0.0622 \\
0.0597 \\
0.0603 \\
0.0612 \\
0.0644 \\
0.0699\end{array}$ \\
\hline $\begin{array}{l}\text { RMS total } \\
(\mu \mathrm{m})\end{array}$ & $\begin{array}{l}\text { Preoperative } \\
1 \text { year } \\
2 \text { years } \\
3 \text { years } \\
4 \text { years } \\
5 \text { years } \\
6 \text { years } \\
7 \text { years }\end{array}$ & $\begin{array}{l}8.333 \pm 3.81 \\
7.713 \pm 3.66 \\
7.688 \pm 3.72 \\
7.662 \pm 3.64 \\
7.638 \pm 3.67 \\
7.622 \pm 3.71 \\
7.609 \pm 3.63 \\
7.596 \pm 3.69\end{array}$ & $\begin{array}{l}0.0244^{*} \\
0.0236^{*} \\
0.0226^{*} \\
0.0219^{*} \\
0.0273^{*} \\
0.0216^{*} \\
0.02 *\end{array}$ & $\begin{array}{l}8.891 \pm 2.97 \\
8.257 \pm 3.07 \\
8.148 \pm 3.11 \\
8.085 \pm 3.03 \\
8.072 \pm 2.92 \\
8.056 \pm 3.05 \\
8.033 \pm 3 \\
8.017 \pm 3.09\end{array}$ & $\begin{array}{l}0.0124^{*} \\
0.0465^{*} \\
0.0388^{*} \\
0.0368^{*} \\
0.0345^{*} \\
0.0332^{*} \\
0.0309 *\end{array}$ & $\begin{array}{l}0.2605 \\
0.2441 \\
0.2663 \\
0.2521 \\
0.2599 \\
0.2613 \\
0.2648 \\
0.271\end{array}$ \\
\hline
\end{tabular}

Note: *Statistically significant $(p<0.05)$.

Abbreviations: TP, thinnest point of the cornea; IVA, index vertical asymmetry; ISV, index of surface variance; IHA, index of height asymmetry; BAD_D, Belin/Ambrosio Enhanced Ectasia Display; ART Max, Ambrosio relational thickness; RMS total, root mean square values; IHD, index of height decentration.

noting that modification in SE values were better in the A-CXL group compared to the S-CXL, but not statistically significant, indicating that both $\mathrm{CXL}$ procedures were efficient.

The present study revealed a reduction in the cylinder value of $0.34 \mathrm{D}$ at 1 year and $0.74 \mathrm{D}$ at 7 years in the A-CXL group and of $0.08 \mathrm{D}$ at 1 year and $0.64 \mathrm{D}$ at 7 years in the S-CXL group. Similarly, Ting et $\mathrm{al}^{49}$ showed that the astigmatism decreased from baseline, but it was not statistically significant at 2 years' follow-up after A-CXL $(p>0.05)$.

Our findings revealed a statistically significant CDVA improvement at 7 years compared to baseline in both groups $(p<0.05)$. Similarly, several studies showed no statistically significant difference in the improvement of CDVA between A-CXL and S-CXL. ${ }^{47,48,51}$ Moreover, Ng et $\mathrm{al}^{33}$ revealed significant visual improvement after S-CXL compared with the A-CXL procedure. Similar results were reported by Ting et $\mathrm{al}^{49}$ concluding that the final CDVA was associated with lower baseline CDVA $(p=0.002)$ and greater $\operatorname{Kmax}(p=0.018)$ at baseline. Moreover, Hashemi et $\mathrm{al}^{11}$ and Wittig-Silva et $\mathrm{al}^{10}$ achieved an increase of the CDVA of $0.12 \log$ MAR at 5-year postoperative and 0.09 $\operatorname{logMAR}$ at 3-year postoperative after S-CXL procedure. Moreover, there are studies $^{56,57}$ which reported better vision improvement after CXL when the preoperative CDVA was under 0.3 $\log$ MAR value. Kanellopoulos et $\mathrm{al}^{54}$ showed an improvement in CDVA in both groups of high-fluence A-CXL (7 $\mathrm{mW} / \mathrm{cm}^{2}$ ) and S-CXL group at 6 months of follow-up.

Our study revealed a statistically significant reduction in the topographical/tomographical parameters such as TP, corneal volume, IHA, ISV, ISA, IHD, BAD_D and ART Max from baseline values in both groups, without any statistically significant difference between the two groups at each time point $(p<0.05)$. Greenstein et $\mathrm{al}^{56}$ noted that HOAs, total coma, 3rd-order coma, trefoil and spherical aberration decreased statistically significantly at 1 year 


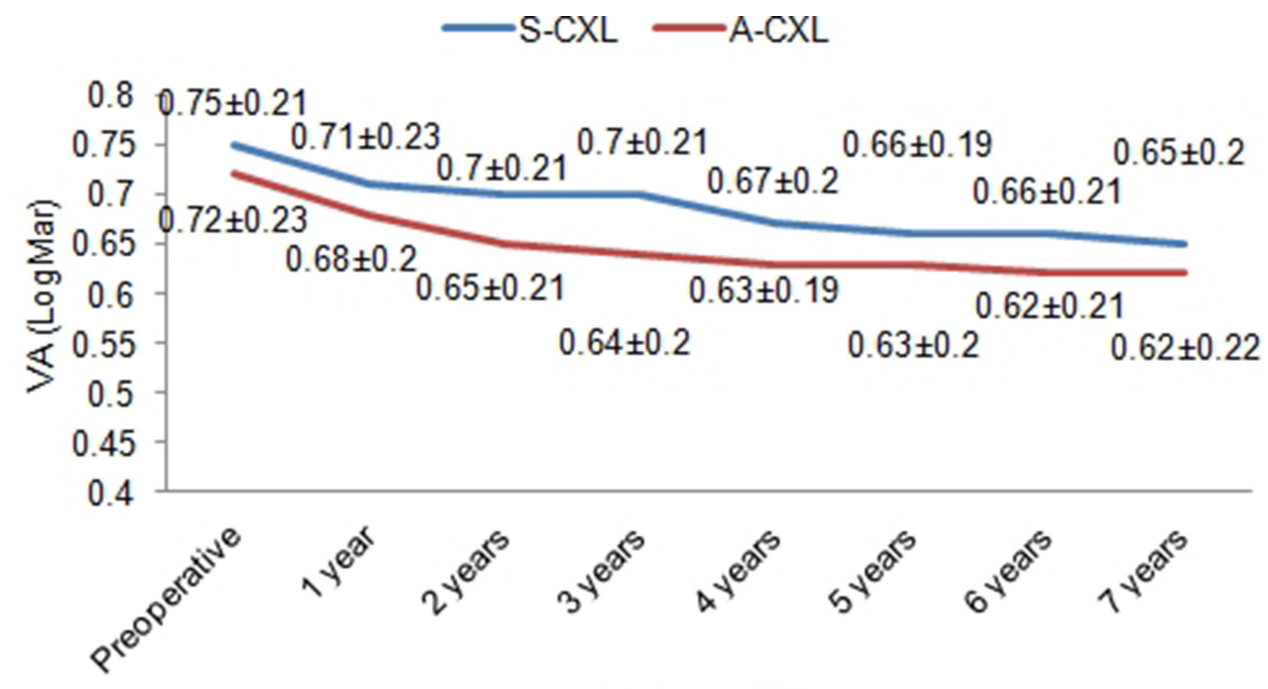

Timepoint

Figure 5 Evolution of UDVA in both groups.

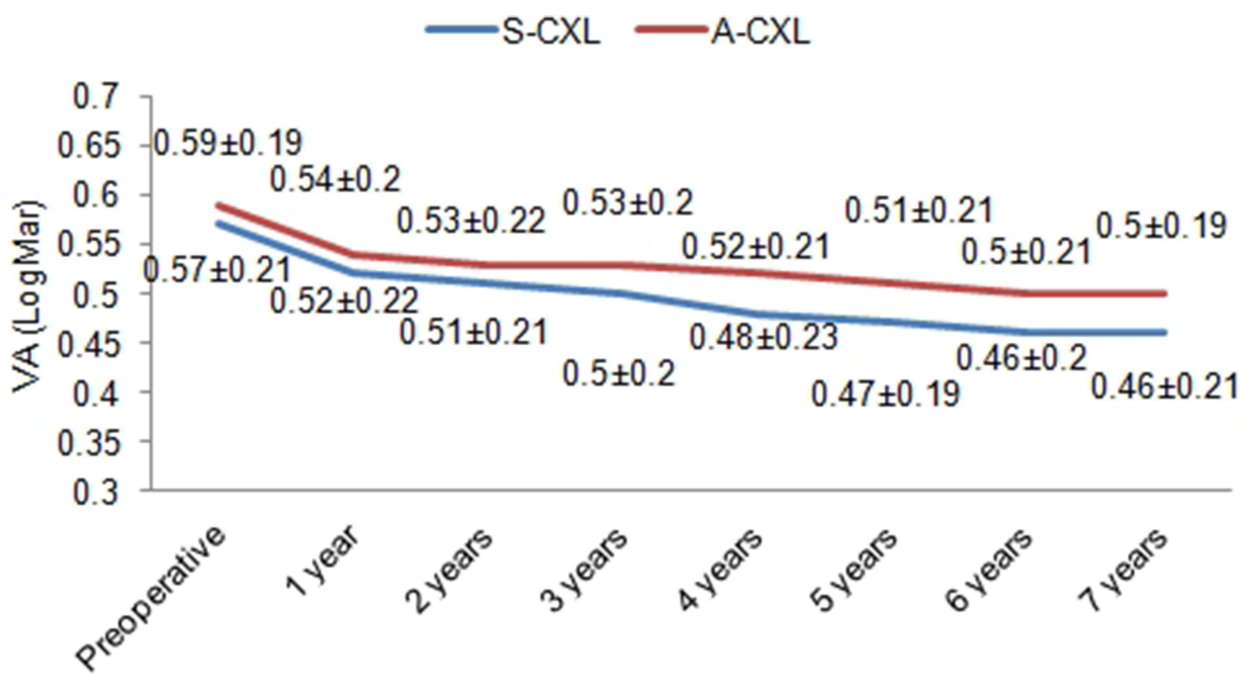

Timepoint

Figure 6 Evolution of CDVA in both groups.

after CXL compared with the control group $(p=0.01)$. The same author demonstrated that modifications in HOAs were not statistically associated with an improvement in visual outcomes. ${ }^{56}$ Furthermore, Shetty et $\mathrm{al}^{36}$ demonstrated improvement in topographic parameters in A-CXL and S-CXL after 12 months of follow-up. Our findings showed that RMS total was not statistically significantly different between the two groups at all time points. Kang et al ${ }^{58}$ demonstrated that, after A-CXL with high UVA energy dose $\left(7.2 \mathrm{~J} / \mathrm{cm}^{2}\right)$ particularly, total root mean square and higher order aberrations improved at 12 to 24 months after CXL.

Our findings revealed that the demarcation line, as an efficacy parameter, was localized at $203 \pm 12.03 \mu \mathrm{m}$ in the A-CXL group and at $211 \pm 13.2 \mu \mathrm{m}$ in the S-CXL group. Kymionis et $\mathrm{al}^{59}$ noted that the location of the demarcation line using the AS-OCT was at $300.67 \pm 41.56 \mu \mathrm{m}$ (range, 240 to $385 \mu \mathrm{m}$ ) and using confocal microscopy was at $306.22 \pm 51.54 \mu \mathrm{m}$ (range, 245 to $417 \mu \mathrm{m}$ ) after highintensity $\left(18 \mathrm{~mW} / \mathrm{cm}^{2}\right)$ UVA irradiation for a 5 -minute 
collagen CXL. Furthermore, Shetty et $\mathrm{al}^{36}$ measured the depth of the demarcation line after four protocols of CXL. They demonstrated that a deeper demarcation line was present in the $3 \mathrm{~mW} / \mathrm{cm}^{2}$ and $9 \mathrm{~mW} / \mathrm{cm}^{2}$ groups and an incomplete one was noted in the higher-intensity CXL groups. Moreover, recently Mazzotta et $\mathrm{al}^{40}$ revealed that the demarcation line at the 1 st postoperative month was at a depth of $332.6 \pm 23.6 \mu \mathrm{m}$ in the overall study cohorts after A-CXL procedure.

The present paper showed a progression of the $\mathrm{KCN}$ after CXL in $3.84 \%$ of cases. Vinciquera et $\mathrm{al}^{42}$ reported $7.4 \%$ of rate failure after S-CXL at up to 13 years of followup, using a combined progression system that includes anterior and posterior curvature and with thickness map together. Thirteen eyes (8.33\%) of 8 patients had a Kmax progression of $1 \mathrm{D}$ within the 2 nd-3rd year follow-up visits, returning to baseline value after $30 \pm 6$ months. All patients with such progression were affected with severe allergic papillary conjunctivitis. No re-treatment was performed in the entire 5-year follow-up period. ${ }^{40}$

A limitation of the present study is that it does not compare the biomechanical parameters between the two groups, although it has a long-term follow-up period and includes a large sample of patients. This study meant to show the stability of keratometric parameters, visual outcomes and topographical/tomographical indices after A-CXL in comparison with the S-CXL procedure at 7 years of follow-up. To our knowledge, this is the first study conducted in Romania, with such a long period of follow-up.

\section{Conclusions}

The long-term outcome of "epi-off" accelerated corneal collagen crosslinking-UVA ( $9 \mathrm{~mW} / \mathrm{cm}^{2}$ for 10 minutes) is similar to standard "epi-off" corneal collagen crosslinking procedure at 7 years follow-up, being an efficient and safe procedure in the treatment of progressive keratoconus.

\section{Author Contributions}

Cristina Ariadna Nicula and Dorin Nicula carried out the surgical procedures and were involved in writing the manuscript and the design. Adriana Elena Bulboacă, Karin Ursula Horvath and Anca Maria Rednik were responsible for methodology, data collection and review process. Ariadna Patricia Nicula and Anca Maria Rednik carried out the statistical analysis and contributed to the design of the paper. All authors contributed to data analysis, drafting or revising the article, gave final approval of the version to be published, aged to the submitted journal, and agree to be accountable for all aspects of the work.

\section{Disclosure}

The authors declare that there are no conflicts of interest regarding the publication of this article.

\section{References}

1. Zadnik K, Barr JT, Gordon MO, Edrington TB; CLEK study Group. Biomicroscopic signs and disease severity in keratoconus. Cornea. 1996;15:139-146.

2. Kennedy RH, Bourne WM, Gyer JA. A 48-year clinical and epidemiologic study of keratoconus. A J Ophthalmol. 1986;101:267-273.

3. Zadnik K, Steger May K, Fink BA, et al. Between-eye asymmetry in keratoconus. Cornea. 2002;21:671-679.

4. Chopra I, Jain AK. Between-eye asymmetry in keratoconus in an Indian population. Clin Exp Optom. 2005;88:146-152.

5. Rabinowits YS. Keratoconus. Surv Ophthalmol. 1998;42:297-319.

6. Spoerl E, Seiler T. Techniques for stiffening the cornea. J Refract Surg. 1999;15(6):711-713.

7. Wollensak G, Spoerl E, Seiler T. Riboflavin/ultraviolet-A-induced collagen crosslinking for the treatment of keratoconus. $\mathrm{Am}$ J Ophthalmol. 2003;135(5):620-627.

8. Caporossi A, Mazzotta C, Baiocchi S, Caporossi T. Long-term results of riboflavin ultraviolet a corneal collagen cross-linking for keratoconus in Italy: the Siena eye cross study. Am J Ophthalmol. 2010;149:585-593.

9. Mazzotta C, Traversi C, Baiocchi S, et al. Corneal collagen cross-linking with riboflavin and ultraviolet A light for pediatric keratoconus: ten-year results. Cornea. 2018;37:560-566.

10. Wittig-Silva C, Chan E, Islam FM, Wu T, Whiting M, Snibson GR. A randomized, controlled trial of corneal collagen crosslinking in progressive keratoconus: three-year results. Ophthalmology. 2014;121:812-821.

11. Hashemi H, Seyedian MA, Miraftab M, Fotouhi A, Asgari S. Corneal collagen cross-linking with riboflavin and ultraviolet A irradiation for keratoconus: long-term results. Ophthalmology. 2013;120:15 $15-1520$.

12. Hersh PS, Stulting RD, Muller D, et al. United States multicenter clinical trial of corneal collagen cross-linking for keratoconus treatment. Ophthalmology. 2017;124(9):1259-1270.

13. Raiskup F, Theuring A, Pillunat LE, et al. Corneal collagen crosslinking with riboflavin and ultraviolet- a light in progressive keratoconus: ten-year results. J Cataract Refract Surg. 2015;41:41-46.

14. Nicula C, Pop R, Rednik AM, Nicula D. 10-year results of standard cross-linking in patients with progressive keratoconus in Romania. J Ophthalmol. 2019;2019:8285649.

15. Mazzotta C, Caragiuli S. Intraoperative corneal thickness measurement by optical coherence tomography in keratoconic patients undergoing corneal collagen cross-linking. Am $J$ Ophthalmol. 2014;157:1156-1162.

16. Mazzotta C, Baiocchi S, Caporossi T, Caragiuli S, Paradiso AL, Caporossi A. Riboflavin $0.1 \%$ for the treatment of keratoconus. Expert Opinion Orphan Drugs. 2013;3:235-240.

17. Mastropasqua L, Lanzini M, Curcio C, et al. Structural modifications and tissue response after standard epi-off and iontophoretic corneal cross-linking with different irradiation procedures. Invest Ophthalmol Vis Sci. 2014;55:2526-2533.

18. Kanelloupoulos AJ. Ten-year outcomes of progressive keratoconus management with the Athens protocol (Topography-Guided partial refraction PRK combined with CXL). J Refract Surg. 2019;35:478-483. 
19. Mazzotta C, Ferrise M. Chemically-boosted corneal cross-linking for the treatment of keratoconus through a riboflavin $0.25 \%$ optimized solution with high superoxide anion release. J Clin Med. 2021;10 (6): 1324.

20. Krueger PR, Herekar S, Spoerl E. First proposed efficacy study of high versus standard irradiance and fractionated riboflavin/ultraviolet a cross-linking with equivalent energy exposure. Eye Contact Lens. 2014;40(6):353-357.

21. Mazzotta C, Traversi C, Paradiso AL, Latronico ME, Rechichi M. Pulsed light accelerated crosslinking versus continuous accelerated crosslinking: one-year results. J Ophthalmol. 2014;2014:604731.

22. Briendly GS. The Bunsen-Roscoe law for the human eye at very short durations. J Physiol. 1952;118(1):135-139.

23. Perez-Straziota C, Gaster R, Rabinowitz Y. Corneal collagen crosslinking for pediatric keratoconus review. Cornea. 2018;37 (6):802-809.

24. Mazzotta C, Baiocchi S, Bagaglia S, Fruschelli M, Meduri A, Rechichi M. Accelerated $15 \mathrm{~mW}$ pulsed-light crosslinking to treat progressive keratoconus: two-year clinical results. J Cataract Refract Surg. 2017;43(8):1081-1088.

25. Mazzotta C, Traversi C, Caragiuli S, Rechichi M. Pulsed vs continuous light accelerated corneal collagen cross-linking: in vivo qualitative investigation by confocal microscopy and corneal OCT. Eye (Lond). 2014;28(10):1179-1183.

26. Rechichi M, Mazzotta C, Giovanni W, et al. Selective transepithelial ablation with simultaneous accelerated corneal cross-linking for corneal regularization of keratoconus: the STARE-X protocol. J Cataract Refract Surg. 2021. doi:10.1097/j.jcrs

27. Waszczykowka A, Jurowski P. Two-year accelerated corneal cross-linking outcome in patients with progressive keratoconus. $J$ of Biomedicine and Biotechnology. 2015;2015(3):325157.

28. Bozkurt E, Ozgurhan EB, Ilkay B, et al. Refractive, topographic, and aberrometric results at 2-year follow-up for accelerated corneal cross-link for progressive keratoconus. $J$ Ophthalmol. 2017;2017:5714372.

29. Ghanem CR, Santhiago MR, Berti T, Netto MV, Ghanem VC. Topographic, corneal wavefront, and refractive outcomes 2 years after collagen crosslinking for progressive keratoconus. Cornea. 2014;33(1):43-48.

30. Gore M, Leucci MT, Koay S, et al. Accelerated pulsed high-fluence corneal cross-linking for progressive keratoconus. Am J Ophthalmol. 2021;221:9-16.

31. Kortuem K, Vounotrypidis V, Athanasiou A, et al. Differences in corneal clinical findings after standard and accelerated cross-linking in patients with progressive keratoconus. BMC Ophthalmol. 2017;222:1-8.

32. Wen D, Li Q, Song B, et al. Comparison of standard versus accelerated corneal collagen cross-linking for keratoconus: a meta-analysis. Invest Ophthalmol Vis Sci. 2018;59:3920-3931.

33. Ng AL, Chan TC, Cheng AC. Conventional versus accelerated corneal collagen crosslinking in the treatment of keratoconus. Clin Exp Ophthalmol. 2016;44:8-14.

34. Cummings AB, McQuaid R, Naughton S, Brennan E, Mrochen M. Optimizing corneal crosslinking in the treatment of keratoconus: a comparison of outcomes after standard- and high intensity protocols. Cornea. 2016;35(6):814-822.

35. Chow VW, Chan TC, Yu M, Wong VW, Jhanji V. One-year outcomes of conventional and accelerated collagen crosslinking in progressive keratoconus. Sci Rep. 2015;5:14425.

36. Shetty R, Pahuja NK, Nuijts RM, et al. Current protocols of corneal collagen crosslinking - visual, refractive and tomographic outcomes. Am J Ophthalmol. 2015;160(2):243-249.

37. Vinciguerra P, Albè E, Trazza S, Seiler T, Epstein D. Intraoperative and postoperative effects of corneal collagen cross-linking on progressive keratoconus. Arch Ophthalmol. 2009;127(10):1258-1265.
38. Belin MW, Duncan JK, Ambrósio R Jr, Gomes JAP. A new tomographic method of staging/classifying keratoconus: the ABCD grading system. Int J Kerat Ect Cor Dis. 2015;4(3):55-63.

39. Belin MW, Duncan JK. Keratoconus: the ABCD grading system. Klin Monbl Augenheilkd. 2016;233(6):701-707.

40. Mazzotta Raiskup F, Hafezi F, Torres-Netto EA, Balamoun AA, Giannaccare G, Bagaglia S. Long term results of accelerated $9 \mathrm{~mW}$ corneal crosslinking for early progressive keratoconus: the Siena eye-cross study 2. Eye and Vision. 2021;8:16.

41. Belin M, Meyer J, Duncan J, Gelman R, Borstrom AR. Assessing progression of keratoconus and cross-linking efficacy: the Belin ABCD progression display. Int J Keratoconus Ectatic Corneal Dis. 2017;6(1):1-10.

42. Vinciquera R, Pagano L, Borgia A, et al. Corneal cross-linking for progressive keratoconus: up to 13 years of follow-up. L Refract Surg. 2020;36(12):838-843.

43. Viswanathan D, Males J. Prospective longitudinal study of corneal collagen crosslinking in progressive keratoconus. Clin Experiment Ophthalmol. 2013;41(6):531-536.

44. Elmassry A, Ahmed OIS, Abdalla MF, Gaballah K. Ten years experience of corneal collagen cross-linking: an observational study of 6120 cases. Eur J Ophthalmol. 2021;31(3):951-958.

45. Schumacher S, Oeftiger L, Mrochen M. Equivalence of biomechanical changes induced by rapid and standard corneal cross-linking, using riboflavin and ultraviolet radiation. Invest Ophthalmol Vis Sci. 2011;52:9048-9052.

46. Wang YM, Chan TC, Yu MCY, Jhanji V. Comparative evaluation of progression rate in keratoconus before and after collagen crosslinking. Br J Ophthalmol. 2018;102:1109-1113.

47. Males JJ, Viswanathan D. Comparative study of long-term outcomes of accelerated and Conventional collagen crosslinking for progressive keratoconus. Eye (Lond). 2018;32:32-38.

48. Sarac O, Caglayan M, Uysal BS, Uzel AG, Tanriverdi B, Cagil N. Accelerated versus standard crosslinking in pediatric keratoconus patients: 24 months follow-up results. Cont Lens Anterior Eye. 2018;:S1367-0484(17):30338-7.29.

49. Ting DS, Rana-Rahman R, Chen Y, et al. Effectiveness and safety of accelerated $\left(9 \mathrm{~mW} / \mathrm{cm}^{2}\right)$ corneal collagen cross-linking for progressive keratoconus: a 24-month follow-up. Eye. 2019;33:812-818.

50. Hashemi H, Fotouhi A, Miraftab M, et al. Short-term comparison of accelerated and standard methods of corneal collagen crosslinking. $J$ Cataract Refract Surg. 2015;41(3):533-540.

51. Vounotripidis E, Athanasiou A, Kortuem K, et al. Long -term data base analysis of conventional and accelerated crosslinked keratoconic mid-European eyes. Graefes Arch Clin Exp Ophthalmol. 2018;256:1165-1172.

52. Elbaz U, Shen C, Lichtinger A, et al. Accelerated $\left(9 \mathrm{~mJ} / \mathrm{cm}^{2}\right)$ corneal collagen crosslinking for keratoconus-A 1 year follow-up. Cornea. 2014;33(8):769-773.

53. Alnawaiseh M, Rosentreter A, Bohm MR, Eveslage M, Eter N, Zumhagen L. Accelerated $\left(18 \mathrm{~mJ} / \mathrm{cm}^{2}\right)$ corneal collagen crosslinking for progressive keratoconus. Cornea. 2015;34(11):1427-1431.

54. Kanellopoulos AJ. Long-term results of a prospective randomized bilateral eye comparison trial of higher fluence, shorter duration ultraviolet A radiation, and riboflavin collagen cross-linking for progressive keratoconus. Clin Ophthalmol. 2012;6:97-101.

55. Chan TC, Chow VW, Jhanji V, Wong VW. Different topographic response between mild to moderate and advanced keratoconus after accelerated collagen cross-linking. Cornea. 2015;34 (8):922-927.

56. Greenstein SA, Hersch PS. Characteristics influencing outcomes of corneal collagen cross-linking for keratoconus and ectasia: implications for patient selection. J Cataract Surg. 2013;39:1133-1140.

57. Toprak I, Yaylali V, Yildirim C. Factors affecting outcomes of corneal collagen cross-linking treatment. Eye (Lond). 2014;28:41-46. 
58. Kang Y, Li S, Liu C, et al. Accelerated epithelium-off corneal cross-linking with high ultraviolet energy dose $\left(7.2 \mathrm{~J} / \mathrm{cm}^{2}\right)$ for progressive keratoconus: 2-year results in a Chinese population. J Refract Surg. 2020;36(11):731-739.
59. Kymionis GD, Tsoulnaras KI, Grentzelos MA, et al. Evaluation of corneal stromal demarcation line depth following standard and a modified-accelerated collagen cross-linking protocol. $\mathrm{Am}$ J Ophthalmol. 2014;158(4):671-675.

\section{Publish your work in this journal}

Therapeutics and Clinical Risk Management is an international, peerreviewed journal of clinical therapeutics and risk management, focusing on concise rapid reporting of clinical studies in all therapeutic areas, outcomes, safety, and programs for the effective, safe, and sustained use of medicines. This journal is indexed on PubMed Central, CAS,
EMBase, Scopus and the Elsevier Bibliographic databases. The manuscript management system is completely online and includes a very quick and fair peer-review system, which is all easy to use. Visit http://www.dovepress.com/testimonials.php to read real quotes from published authors. 